\title{
Agricultura y desarrollo rural en Colombia 2011-2013: una aproximación*
}

\author{
Agriculture and rural development in \\ Colombia 2011-2013: an approach
}

\section{Agricultura e desenvolvimento rural na Colômbia 2011-2013: um abordagem}

Johanna Inés Cárdenas Pinzón** Luis Eudoro Vallejo Zamudio***

Fecha de recepción: 30 de noviembre de 2015

Fecha de aceptación: 2 de junio de 2016

Artículo resultado de la actividad del grupo de investigación Modelos de Desarrollo Económico en América Latina (MODEAL) de la Escuela de Economía de la Universidad Pedagógica y Tecnológica de Colombia, Tunja (UPTC), con el proyecto titulado Líneas estratégicas para la locomotora agricultura y desarrollo rural en Colombia 2010-2013: alcances y limitaciones. Agradecemos el apoyo brindado por la Dirección de Investigaciones de la UPTC para el desarrollo de esta investigación, y por el estímulo otorgado a la coautora de este documento.

** Magíster (c) en Economía. Docente catedrática de la Escuela de Economía de la UPTC, Joven Investigadora UPTC 2014. Correo electrónico: johanna.cardenas@uptc.edu.co

*** Doctor en Economía Universidad de Barcelona. Profesor titular de la Escuela de Economía y coordinador del grupo de investigación MODEAL de la UPTC, Tunja. Colombia. Correo electrónico: luvallejo1@hotmail.com 


\title{
Resumen
}

El objetivo de este artículo es presentar una revisión bibliográfica del concepto de desarrollo rural y del papel de la agricultura y el desarrollo rural en la actividad económica, así como determinar el comportamiento que ha tenido el sector agropecuario en Colombia en el periodo 2011-2013, de acuerdo con las estrategias propuestas para el sector en el Plan Nacional de Desarrollo 20102014. Se concluyó, en términos generales, que la política agraria en Colombia debe ser abordada bajo la nueva visón del desarrollo rural, la cual debe incluir actividades que se desarrollen en el área rural, y el gran reto debe ser replantear el hecho de que el sector rural solamente se limita al sector productivo.

\section{Palabras clave: agricultura, desarrollo rural, política agraria, sector rural.}

Clasificación JEL: O13, Q1, Q18

\begin{abstract}
The aim of this paper is to present a literature review of the concept of rural development and the role of agriculture and rural development in economic activity, and to determine the advances made in Colombia's agricultural sector in the period 2011-2013, according to the proposed strategies for the sector in the National Plan of Development 2010-2014. It was concluded, in general terms, that agricultural policy in Colombia should be approached from the new vision of rural development, which must include activities taking place in rural areas, and the challenge should be rethinking the fact that the rural sector is limited only to the productive sector.
\end{abstract}

Keywords: agriculture, rural development, agricultural policy, rural sector. 


\section{Resumo}

O objetivo deste artigo é apresentar uma revisão da literatura sobre o conceito de desenvolvimento rural e do papel da agricultura e desenvolvimento rural da atividade econômica e determinar o comportamento que teve no sector agrícola na Colômbia no período 2011-2013, de acordo com as estratégias propostas para o setor no Plano Nacional de Desenvolvimento 2010-2014. Concluiuse, em termos gerais, que a política agrícola na Colômbia deve ser tratada no âmbito da nova visão do desenvolvimento rural, que deve incluir atividades realizadas nas áreas rurais, e o grande desafio deve ser repensar o fato de que o setor rural é limitado apenas para o setor produtivo.

Palavras-chave: agricultura, desenvolvimento rural, política agrícola, setor rural. 


\section{INTRODUCCIÓN}

Uno de los objetivos de política económica es lograr un crecimiento sostenido del producto, que genere empleo y, por tanto, mejore la calidad de vida de los habitantes. La meta de crecimiento anual propuesta por el Plan Nacional del Desarrollo 2010-2014, es de más del $6 \%$, para garantizar un crecimiento que sea sostenido y sostenible social y ambientalmente, basado en tres pilares: a) la innovación, b) la competitividad y productividad y c) el dinamismo de las locomotoras, de manera que directa o indirectamente lideren el crecimiento y generen empleo.

En el Plan Nacional de Desarrollo (PND) Prosperidad para todos 2010-2014, aprobado por medio de la Ley 1450 de 2011, el capítulo III hace énfasis en el crecimiento sostenible y la competitividad, y menciona que uno de los pilares para lograr en 2014 un crecimiento del producto de $6.2 \%$, es la activación de las cinco locomotoras del desarrollo: nuevos sectores basados en la innovación, agricultura y desarrollo rural, vivienda y ciudades amables, desarrollo minero y expansión energética, e infraestructura de transporte. Estas están definidas en el PND como los sectores que avanzan más rápido que el resto de la economía, sin dejar de lado los otros sectores productivos que pueden acelerar el crecimiento por sí solos o ser "jalonados" por algunos de los sectores locomotora y, por supuesto, teniendo en cuenta la sostenibilidad social $\mathrm{y}$ ambiental.
Las bases del PND 2010-2014 reconocen la importancia que, sin duda, tiene la agricultura en la economía por su contribución al PIB, la generación de empleo, la presencia en el sector rural y la producción de divisas vía exportaciones. Sin embargo, todo su potencial puede ser aprovechado si se solucionan los cuellos de botella existentes: baja competitividad y productividad de algunos rubros que tienen una contribución importante en el PIB sectorial, limitada disponibilidad de infraestructura para el transporte y la comercialización de los productos agropecuarios, restricciones para ampliar y diversificar los mercados, baja capacidad para enfrentar factores exógenos y estabilizar las inversiones en el campo, dificultad de la población rural para desarrollar su potencial productivo y desequilibrios regionales (PND, 2010-2014).

Este trabajo se enfoca en el desempeño de la agricultura y desarrollo rural para el periodo 2011-2013, propuesto como sector líder en el PND 2010-2014. En la primera parte se examinan algunos aportes teóricos sobre el desarrollo rural; en la segunda, se presenta la importancia de este sector en la actividad económica; en la tercera, se expone el comportamiento de la agricultura en los tres primeros años del primer Gobierno de Juan Manuel Santos, con base en la información del Sistema Nacional de Evaluación de Gestión y Resultados (Sinergia) y de los informes presentados por la Presidencia al Congreso de la República; y por último, se plantean las conclusiones. 


\section{EL CONCEPTO DE DESARROLLO RURAL}

El desarrollo rural, generalmente, hace referencia a las acciones propiciadas para mejorar la calidad de vida de los habitantes de las áreas rurales. Para Ceña (1993), es un proceso de mejora del bienestar de la población rural y de la contribución que el área rural hace de forma al bienestar de la población, ya sea urbana o rural, basándose en sus recursos naturales.

Para Trivelli, Escobal y Revesz (2009), desde el punto de vista de un plano operativo, el desarrollo rural tiene como objetivo aumentar la cantidad y calidad de los activos de las personas e instituciones para lograr un mayor nivel de ingresos. Así mismo, busca generar un impacto en las capacidades humanas, asistencia técnica, créditos y donaciones, entre otros.

Sin embargo, Restrepo y Bernal (2014) consideran que existe una nueva visión de desarrollo rural que se puede definir por medio de tres postulados:

a) El campo de acción del desarrollo rural es muy amplio y por tanto no debe entenderse como lo concerniente a las actividades agrícolas y pecuarias, sino que además tiene que ver con las acciones que contribuyan a mejorar la calidad de vida ${ }^{1}$ de la población rural, a esto se la ha denominado la nueva ruralidad. b) La provisión de "bienes públicos" es fundamental, a cambio de que solo se otorguen subsidios directos que la mayoría de las veces llegan a manos de quienes menos los necesitan: "Un desarrollo rural con enfoque territorial, en el que se privilegie la dotación de bienes públicos, por oposición al método simplista de otorgar subsidios directos regresivos a los que más capacidades tiene para pedir, que no son necesariamente quienes más necesitan el apoyo del estado" (Restrepo \& Bernal, 2014, p. 146).

De acuerdo con Restrepo y Bernal (2014), también es importante capacitar a los municipios acerca del funcionamiento del Plan de Ordenamiento Territorial Rural, pero haciendo énfasis en que no vale la pena plantear un ordenamiento desde el punto de vista municipal, porque podría ir en sentido contrario de algún municipio vecino, entonces es ahí en donde se debe adoptar una noción más amplia de los límites territoriales.

c) Las inversiones asociadas al desarrollo rural deben ser intensivas en áreas en donde hay mayor pobreza relativa, a fin de que la inversión pública tenga considerable impacto en la calidad de vida de la población rural.

El enfoque de las políticas públicas actuales debe abordar esta nueva visión del desarrollo rural “... desde una perspectiva holística que va más allá de

Infraestructura, salud, ciencia y tecnología, servicios públicos, ecoturismo, TIC (Restrepo \& Bernal, 2014).

Las comillas son de los autores. Estos bienes hacen referencia a asistencia técnica, riego drenaje, vivienda rural y tecnología (Restrepo \& Bernal, 2014). 
la agricultura, para incluir un sin número de actividades que se desarrollan en las zonas rurales. Así mismo, la actividad agrícola también debe entenderse hoy como multifuncional, dejando de limitarla puramente a lo productivo" (Restrepo \& Bernal, 2014, p. 151).

Para Trivelli (2005) existe una visión más amplia de lo rural: "El mundo rural es más diverso y complejo que lo agropecuario, pero lo agrario sigue siendo importante y muchas veces centro de las actividades sociales y económicas" (Trivelli, 2005, p. 9); dicha autora coincide con Restrepo y Bernal (2014) al reconocer que el desarrollo rural debe ser visto desde lo territorial, en conjunto y en ámbito multisectorial.

Pérez (1998) considera que el desarrollo rural "... debe buscar la equidad territorial, de género y social, en el acceso a bienes, servicios y demás beneficios del desarrollo. La equidad es una meta que, en los albores del siglo XXI, está aún muy distante, ya que los procesos de concentración de la riqueza y de los medios de producción siguen siendo factores que prevalecen" (Pérez, 1988, p. 10).

Además, es necesario dejar atrás la idea de que las zonas rurales son atrasadas y las urbanas las desarrolladas, se debe reconocer que lo rural está interrelacionado con lo urbano, dado que se presentan relaciones entre las dos áreas (que van más allá del hecho de ser proveedor de alimentos) de tipo comercial, de flujos financieros y de recursos humanos y natu- rales (Pérez, 1998). Para lograr disminuir la brecha existente entre los dos sectores es necesario poner en marcha programas de desarrollo rural que involucren a la población rural y asegurar la atención a los pequeños productores agropecuarios (Junguito, Perfeti \& Becerra, 2014).

Para el Banco Interamericano de Desarrollo (BID), el objetivo general del desarrollo rural es mejorar de manera sostenible la calidad de vida de la población rural de ingresos bajos, procurando que la economía campesina contribuya al proceso de desarrollo nacional. Para esto, el BID propone promover la economía del sector rural por medio del mejoramiento de la producción y los ingresos de la población, para lo cual se debe incrementar el rendimiento de las unidades campesinas, desarrollar nuevas actividades no agropecuarias y propiciar el mejoramiento de la condiciones laborales, entre otros.

Es importante resaltar que el Informe Nacional de Desarrollo Humano (PNUD, 2011) incorpora la agricultura y el desarrollo rural en la agenda del desarrollo humano, porque reconoce como elementos básicos de la estructura agraria, la estructura de la tenencia de la tierra, el uso productivo de los recursos, las relaciones laborales y sociales, las relaciones con el mercado y las relaciones con el sistema político y el Estado.

Desde lo normativo, el desarrollo rural debe enfocarse en alcanzar un crecimiento que no incremente las desigualdades sociales, 
sino que, por el contrario, logre una mayor equidad en la distribución del ingreso, procurando evitar la sobreexplotación de los recursos naturales y promoviendo la sostenibilidad ambiental (Hernández \& Becerra, 2013).

Sepúlveda et al., (2003) realizaron una interesante cronología de la evolución de las ideas sobre desarrollo rural, que permite ubicar al lector en los principales modelos de desarrollo rural desde la posguerra:

1950-1960: en este periodo se hablaba del modelo de la economía dual, la agricultura como sector rezagado, el desarrollo comunitario, la tenencia de la tierra y se tenía una visión peyorativa del campesinado.

1960-1970: para esta década, la agricultura era vista como motor del crecimiento, se empieza a hablar de reforma agraria, revolución verde, mecanización de la extensión agrícola, y el campesino era visto como agente económico racional.

1970-1980: en esta época el interés se manifestaba por la redistribución con crecimiento, las necesidades básicas, el desarrollo rural integrado, las políticas agrícolas estatales, el crédito agrícola estatal, el sesgo urbano, la innovación inducida, la revolución verde, el encadenamiento del desarrollo rural.

1980-1990: en este periodo se presenta un ajuste estructural, comienza la liberación de los mercados, crecimiento de las ONG, evaluación rural rápida, investigación sobre sistemas de producción agrícola, seguridad alimentaria y análisis de las hambrunas, investigación y desarrollo concebidos como proceso y no como producto, mujer y desarrollo, alivio de la pobreza.

1990-2000: las ideas de desarrollo para esta década se enfocaron en la evaluación rural participativa, la investigación y el desarrollo orientados por los actores, las redes de seguridad rural, el desarrollo humano, el capital social, el capital humano, el enfoque de género y desarrollo, ambiente y sostenibilidad, reducción de la pobreza.

2000-: para el nuevo milenio se empieza a hablar de medios de vida sostenibles, gobernabilidad, descentralización, crítica de la participación, enfoques sectoriales amplios, protección social, erradicación de la pobreza.

Al observar esta cronología, se percibe la evolución sobre el concepto de desarrollo rural, que da cuenta de que este tipo de desarrollo está incluido en los objetivos de desarrollo del milenio ${ }^{3}$.

\footnotetext{
Los objetivos de desarrollo del milenio de la ONU son: erradicar la pobreza extrema y el hambre, lograr la enseñanza primaria universal, promover la igualdad entre los sexos y el empoderamiento de la mujer, reducir la mortalidad de los niños menores de cinco años, mejorar la salud materna, combatir el VIH/SIDA, la malaria y otras enfermedades, garantizar la sostenibilidad del medio ambiente y fomentar una alianza mundial para el desarrollo (Informe ODM, 2015).
} 


\section{Desarrollo rural en Colombia}

La concepción del desarrollo rural en Colombia hay que enmarcarla en los modelos de desarrollo a nivel global. Por ello es necesario tener en cuenta que desde los años cincuenta del siglo pasado hasta el presente se pueden considerar dos modelos: el de sustitución de importaciones y el modelo neoliberal.

El modelo de sustitución de importaciones o de desarrollo "hacia adentro" se basó en los postulados de la Cepal (Comisión Económica para América Latina), cuyos principios básicos tienen que ver con la concepción "centro-periferia", la tendencia al deterioro de los términos de intercambio, la industrialización y la planeación y el mercado.

La Cepal insiste en la necesidad de obtener un mayor nivel de crecimiento, para ello, es determinante aumentar sustancialmente la productividad del trabajo y de esta forma elevar los niveles de vida de la población (Rodríguez, 1981). En el caso colombiano, las ideas de la Cepal se van a reflejar en el Plan Decenal de Desarrollo (1960-1970). En dicho plan, la orientación teórica y las técnicas de programación de la mencionada institución van a estar presentes, y uno de los objetivos centrales es alcanzar un crecimiento del $5.6 \%$ anual.

En Colombia, y se puede generalizar para el resto de América Latina, en la segunda mitad del siglo pasado (en el lapso comprendido entre 1960-1990) se implementaron tres programas básicos para enfrentar la pobreza rural (Jaramillo, Perfetti \& Ramirez, 1991): la reforma agraria, la elevación tanto de los ingresos como el bienestar de los campesinos, y por último, un enfoque integral que combina los dos anteriores.

En el modelo de sustitución de importaciones, en relación con el sector agrícola se planteaba que el problema del campo colombiano tenía que ver más con la tenencia de la tierra, que con niveles de productividad, y que lo importante era, por una parte, generar una reforma agraria integral que diera oportunidad a los trabajadores del campo para acceder a la propiedad sobre la tierra, y, por otra, ampliar la frontera agrícola y realizar ciertas mejoras técnicas marginales que respondieran a la disponibilidad de capital $\mathrm{y}$ de trabajo, pero que no condujera a una mecanización intensiva.

En los años sesenta, como bien lo planeta Bejarano (1982), los dos problemas más apremiantes en Colombia eran el desempleo y el problema agrario. Según él, la política de reforma agraria no se orientaba a resolver las dificultades sociales por concentración de la tierra en algunas regiones, sino, más bien, a favorecer la retención de la fuerza de trabajo en el campo y de esta forma evitar la presión por puestos de trabajo que generaba el desplazamiento de fuerza de trabajo al sector urbano, es decir, se diseñó con el fin de aumentar el empleo rural.

Balcázar (1985), sobre el particular, argumenta que en lo político-jurídico 
la política agraria se expresa en las simuladas "pretensiones reformistas" de la Ley 135 de 1961, para resolver las contradicciones entre la burguesía y los terratenientes, y que en lo económico, lo que propició fue:

El fortalecimiento y definitiva consolidación del impulso al desarrollo agrícola sobre la base de la gran propiedad territorial... las únicas acciones efectivas de reforma agraria fueron realizadas en virtud de la iniciativa de movimientos campesinos que se desarrollaron a partir de "invasiones" a latifundios y "toma" efectiva de posesión (Balcazar, 1985, p. 73).

El intento de reforma agraria fue liderada por Carlos Lleras, pero con el cambio de Gobierno, en 1970, el presidente Pastrana Borrero, con asesoría de Lauchlin Currie, consideró que el problema del campo colombiano no era la tenencia de la tierra, sino que lo ideal era mejorar las condiciones de producción y productividad del campo, y así quedó plasmado en el Plan de las Cuatro Estrategias (1972), y por ello se eliminó el programa mencionado. $\mathrm{Si}$ una de las estrategias del referenciado plan era incrementar la producción y productividad agrícola, esta se alcanzaba, siempre y cuando las dos primeras se realizaran (impulso a la construcción y el incremento y diversificación de las exportaciones), ya que en la medida en que se incrementa la productividad en el campo, va a presentarse una expulsión de trabajadores, los cuales deben tener oportunidad de ser ocupados en otras actividades (se suponía que en la construcción y en las exportaciones). Así mismo, incrementar la producción agrícola era necesario para abastecer eficientemente de alimentos al sector urbano y para ofrecer materias primas requeridas en la industria.

Una vez descartado el proyecto de reforma agraria como política clave para el campo, se introduce el programa de Desarrollo Rural Integrado (DRI), hacia 1975. El DRI se erige en el proyecto productivo orientado a modernizar y a incrementar la producción de alimentos, sobre todo en las zonas de minifundio. El programa DRI abarcaba una serie de acciones e inversiones de diferentes aspectos para garantizar un desarrollo integral, tales como, elementos productivos (asistencia técnica y crédito), de mercadeo (comercialización), de infraestructura física (carreteras veredales, acueductos, electrificación) y de asistencias sociales como salud y educación (Kalmanovitz \& López, 2006).

El DRI va a intentar ofrecer condiciones atractivas a los campesinos para evitar su desplazamiento, es decir: "Se convierte en un mecanismo de retención de la fuerza de trabajo en el campo, pero ya no para prolongar la economía de simple subsistencia, como lo quería Lleras Restrepo, sino para integrarla al mercado, fortaleciendo la producción de bienes salario de origen agrícola" (Bejarano, 1982, p. 266). 
Bejarano (1982) es claro al plantear que a diferencia de los sesenta, el DRI tiene la finalidad explícita de vincular a los campesinos a la producción para el mercado, generando requisitos de supervivencia a la economía campesina, no distribuyendo tierras, lo cual avalaría "una producción de subsistencia", sino por medio de vigorizar las situaciones internas de esta economía campesina, lo cual aseguraría un "ingreso de subsistencia" a través de la integración al ámbito de la comercialización.

El DRI, en el Gobierno de Turbay Ayala se trasladó del DNP (Departamento Nacional de Planeación) al Ministerio de Agricultura, pero dicho cambio lo desmejoró y lo expuso a las fluctuaciones políticas del mencionado ente. Tanto en la administración de Belisario Betancur como en la de Virgilio Barco, se orientó el DRI a combatir la pobreza rural, desde luego con algunos matices.

A partir de los noventa del siglo pasado, se instaura el neoliberalismo con la política de apertura económica. En el Plan de Desarrollo: La Revolución Pacífica (1990-1994), en el prólogo del documento, realizado por el presidente Gaviria, se hace una crítica a la sustitución de importaciones y a lo que ha sido la intervención del Estado. Se argumenta que la visión según la cual el Estado podía actuar en diferentes frentes $\mathrm{y}$ actividades, fue importante en el pasado, pero que es factible reorientarla y postular la necesidad de que el Estado opere en actividades de tipo social.
En el modelo que se implementa en Colombia desde 1990 hay una orientación neoliberal. Para este, el Estado no debe participar en la actividad productiva, pues es el sector privado el mejor administrador de la producción. En consecuencia, habría que estimular la privatización. Lo anterior se basa en el principio de que el mercado es el mejor asignador de los recursos, y todo aquello que distorsione el precio de un bien o servicio, contribuye a la ineficiencia y al despilfarro de estos.

A partir del modelo neoliberal se va a enfatizar en una política macroeconómica orientada, por una parte, a un presupuesto equilibrado (es decir: ingresos del estado=gastos del Estado), y por otra, a una política monetaria en la que la oferta monetaria crezca a una tasa constante; además, se desmontan tanto los subsidios a las exportaciones como las restricciones a las importaciones, así mismo, un manejo de tasa de cambio flexible.

Una vez se instaura el modelo neoliberal, lo que esperan tanto sus diseñadores, como sus partidarios, es que los agricultores actúen en los mercados de bienes y de factores sin ningún tipo de restricciones. Por ello, es válida la siguiente valoración:

La visión neoliberal concibe la problemática agraria desde una óptica productivista (la competitividad) de los mercados y de la disminución de la acción del Estado. Su discusión por tanto no se centra en la estructura agraria sino en el desarrollo de los mercados de factores incluida 
la tierra, y en los incentivos para dinamizarlos en lugar de redistribuirlos. Si la concentración de la propiedad rural se articula con la productividad, el Estado no debe intervenir. De otra parte, concibe que el Estado no debe sostener per se a las economías campesinas, sino que éstas deben modernizarse $\mathrm{y}$, por tanto, reubicar la población que no es viable económicamente en el mercado, sólo temporalmente se justifica que el Estado mantenga programas de desarrollo rural (Machado, 2002, pp. 295-296).

Como puede apreciarse, el concepto de desarrollo rural en las nuevas condiciones va a cambiar y es pertinente replantearlo a la luz de la nueva situación. Por ello, a continuación se describirán los aportes que sobre el particular han realizado algunos autores nacionales.

Para Machado (1991), el desarrollo rural es un proceso de cambio de las sociedades locales o rurales, que se realiza en un ambiente democrático incluyente, o por medio de una modernización incluyente, en el que intervengan todos los actores sociales, lo público y lo privado, y en el que las organizaciones campesinas y algunas ONG desempeñen un papel trascendental.

Por ello, Machado (1991) considera que en esa noción de desarrollo rural es necesario tener en cuenta las siguientes dimensiones: la espacial, la política, la institucional, la productiva y económica, la de manejo de los recursos naturales y la sostenibilidad y, por último, la dimensión rural-urbana. De hecho, según el autor, en esta noción de desarrollo rural, y teniendo en cuenta las dimensiones antes descritas, el Estado se convierte en una institución que posibilita el desarrollo, y la comunidad en un actor principal y es la gran favorecida, pero a partir de su propia demanda y no persuadida por entes o funcionarios públicos.

Otro de los autores nacionales que aportó ideas relevantes sobre la conceptualización del desarrollo rural fue Jesús Antonio Bejarano. Él hizo contribuciones interesantes sobre el tema rural en el siglo pasado, pero por restricciones de espacio solo se mencionará lo que planteó el último decenio de la centuria anterior.

Sobre el tema agrario, Bejarano (1998), para el periodo en mención, y basado en Reynolds (1975), va a plantear que el análisis del sector agrícola debe realizarse en un enfoque de equilibrio general, en el que las políticas agrícolas deben asimilarse como parte integrante del marco general de las políticas y, precisa, que en las estrategias de desarrollo deben darle mayor valoración al sector agrícola, desde luego, aceptando que el crecimiento del sector puede ser menor que el resto de sectores de la economía. Él considera que en el marco de análisis del equilibrio general deben tenerse en cuenta tres elementos relevantes:

a) El problema de las interdependencias; b) los impactos de las políticas 
macroeconómicas sobre el desarrollo agropecuario y los impactos del desarrollo agropecuario sobre el equilibrio macroeconómico, y c) la atención a las complementariedades intersectoriales, en las que pudieran señalarse de manera particular interdependencias crecientes en términos de procesos como empleo, pobreza y la dinámica y composición sectorial del crecimiento económico (Bejarano, 1998, p.10)

Así como Bejarano examinó el papel de la agricultura en el contexto del desarrollo nacional para la última década del siglo pasado, a la luz de la nueva realidad, va a revaluar el concepto de lo rural. En uno de sus últimos artículos, Bejarano (1998a) va a describir lo que él llamó la "dimensión de la revalorización de lo rural", la cual consta de los siguientes elementos: en primer lugar la revalorización cultural, que para él, es la más importante y es percibir "lo rural como una nueva, aceptable y mejor alternativa de vida" (Bejarano, 1998a, p.13); la segunda dimensión es la económica, en la que se destaca el aporte no solo de la agricultura, sino de lo rural al crecimiento global, como también al crecimiento liderado por la agricultura, de igual manera la endogeneidad del cambio agrícola y rural. La tercera dimensión es la socioeconómica, en esta se destaca el aporte de lo rural al desarrollo sostenible, al crecimiento económico, a la reducción de la pobreza y a la generación de empleo. Y por último, la revalorización sociopolítica, en esta subraya cuatro aspectos: el primero, el papel de la erosión de las viejas estructuras de poder y formas de dominación local; el segundo, en las actuales circunstancias lo destacable no es la dicotomía rural- urbano, sino la local-global; el tercero, la alteración en la naturaleza de las demandas colectivas.

El autor puntualiza que si bien las comunidades rurales demandan tierras y acceso a activos para las unidades productivas, estas dos posiciones no son las más apremiantes, sino que 10 importante es la reconstrucción de redes sociales, es decir, las comunidades demandan servicios, infraestructura, en general, bienes públicos; y por último, al derrumbarse el Estado de bienestar aparece la "sociedad del riesgo", que conduce de nuevo al fortalecimiento de las comunidades y redes sociales, básicamente rurales o de composición rural, para poder vivir en un mundo con incertidumbre y con riesgo.

El DRI funcionó hasta el 2003, a partir de ese año, la administración del presidente Álvaro Uribe Vélez creó el Incoder (Instituto Colombiano de Desarrollo Rural), ente que reemplazó al Instituto Colombiano de la Reforma Agraria (Incora), al Instituto Nacional de Adecuación de Tierras (Inat), al Fondo de Cofinanciación para la Inversión Rural (DRI) y al Instituto Nacional de Pesca y Agricultura (Inpa). Estas cuatro instituciones fueron suprimidas y sus funciones pasaron al Incoder. El Incoder estuvo adscrito al Ministerio de Agricultura y Desarrollo Rural, y su función principal era realizar y coordinar 
las políticas de desarrollo rural integral ordenadas por el Gobierno nacional, facilitándoles a las comunidades rurales el acceso a factores productivos y bienes públicos, con el fin de mejorar su calidad de vida.

Luego del estudio realizado por la Misión para la Transformación del Campo (dirigido por José Antonio Ocampo), se liquidó a finales de 2015, ya que la Misión recomendó que en su reemplazo se crearan la Agencia de Desarrollo Rural y la Agencia Nacional de Tierras, debido a que "se reconoce ampliamente que la consolidación de cuatro instituciones con tradiciones totalmente diferentes en una sola, el Incoder, terminó por deteriorar cada una de las partes" (Misión Rural para la Transformación del Campo, 2014, p.19).

\section{El desarrollo rural en el proceso de paz}

Para finalizar, se debe destacar que en Colombia, el logro de un verdadero desarrollo rural con equidad depende en gran parte del éxito del proceso de paz que actualmente lleva a cabo el Gobierno de Colombia con las Fuerzas Armadas Revolucionarias de Colombia- Ejército del Pueblo (FARC-EP), ya que el primer punto de la Agenda del Acuerdo General (339 de 2012 de la Presidencia de la República de Colombia) está enfocado en la política de desarrollo agrario integral, el cual reconoce que el desarrollo del sector es fundamental para impulsar la integración de las regiones y el desarrollo social y económico equitativo en el país.
El 26 de mayo de 2014 se anunció el acuerdo del primer punto de las conversaciones de paz en la Habana (Cuba), acuerdo que fue denominado "Hacia un nuevo campo colombiano: Reforma Rural Integral", en la mencionada reforma se propone el inicio de transformaciones estructurales del sector agrario en Colombia con condiciones de equidad y democracia, contribuyendo con el principal objetivo del proceso de fin del conflicto y construcción de una paz durable y verdadera (Restrepo \& Bernal, 2014). Aunque todos los acuerdos a los que se lleguen deben ser aprobados por medio de un referendo ciudadano.

Sin duda, con el proceso de paz y una vez aprobado el primer punto de la agenda de negociación en la Habana, entre el Gobierno nacional y las Fuerzas Armadas Revolucionarias de Colombia (FARC-EP), la propuesta de reforma al campo es considerable, y por ello, las partes suscribieron lo que se conoce como Reforma Rural Integral (RRI). De hecho, con la RRI se trata de combatir no solo la pobreza y la desigualdad en el campo colombiano que, como se describirá más adelante, alcanzan niveles escandalosos, sino una serie de políticas orientadas a que la población rural eleve su nivel de bienestar, por ello en el documento se afirma:

Que si bien este acceso a la tierra es una condición necesaria para la transformación del campo, no es suficiente por lo cual deben establecerse planes nacionales 
financiados y promovidos por el Estado destinados al desarrollo rural integral para la provisión de bienes y servicios públicos como educación, salud, recreación, infraestructura, asistencia técnica, alimentación y nutrición, entre otros, que brinden bienestar y buen vivir a la población rural. (RRI, 2014, p. 1)

De hecho, la RRI plantea una serie de lineamientos interesantes sobre desarrollo rural, pero tal vez, los más llamativos tienen que ver con el enfoque territorial del desarrollo rural, es decir, que los planes y programas convenidos en la RRI deben tener un enfoque territorial, esto es, que en cada región debe tenerse en cuenta las necesidades, características y particularidades sociales, culturales y económicas de los territorios y las comunidades rurales para que las medidas aplicadas sean más eficientes y respondan a lo que efectivamente las comunidades demandan en cada comarca. De igual manera, es oportuno destacar que la RRI concibe que el desarrollo rural no solo abarque actividades agropecuarias, sino que incluya otros sectores como el transporte, el financiero, la administración pública, el comercio, los servicios sociales, entre otros.

Eduardo Sarmiento (2014) reconoce que las negociaciones han avanzado, porque la reforma agraria integral le da prioridad a los pequeños productores para que atiendan el abastecimiento de alimentos y que el Gobierno les suministrará la tierra y su preparación para hacerla efectiva. Y también admite que surgieron avances en la precisión de las necesidades y disponibilidades de tierras, así como en la transferencia fiscal para lograr reducir la pobreza rural.

\section{PAPEL DE LA AGRICULTURA DENTRO DE LA ACTIVIDAD ECONÓMICA}

El sector agropecuario es de gran importancia para el crecimiento económico de los países, además de ser fuente de alimentos y de materias primas para la industria, es, por excelencia, uno de los sectores que genera empleo y divisas a través de las exportaciones, $\mathrm{y}$, por tanto, contribuye al crecimiento y desarrollo económico. En Colombia, el sector genera más del $20 \%$ de empleo en el país, y casi el $50 \%$ en el sector rural (Leibovich \& Estrada, 2008).

"Desde el punto de vista económico, la agricultura es un sector que ha mostrado una gran estabilidad y ha contribuido en no pocas ocasiones a amortiguar la volatilidad de las tasas de crecimiento global de la economía y los efectos de los shocks externos" (Sepúlveda et al., 2003, pp. 19-20).

Para Shultz (1968), cuando un país logra poner en desarrollo su sector agrícola, se presenta abundancia de alimentos, aumento de la renta, y el gasto en comida de la nación es proporcionalmente menor a los ingresos recibidos. Shultz expone que la agricultura tradicional puede llegar a ser un sector productivo de la economía, 
pero esto depende de la inversión que se haga en dicho sector; aunque él aclara que el problema es de inversión, mas no siempre de disponibilidad de capital.

El Plan Nacional de Desarrollo 20102014 (PND 2010-2014) menciona la relevancia de esta locomotora en el éxito de las políticas del Gobierno enfocadas a la restitución de tierras ${ }^{4}$ y la reparación de víctimas, dado que el reintegro de los campesinos desplazados a sus tierras, promueve y fomenta el crecimiento y desarrollo del sector agropecuario. El PND destaca la importancia de convertir las ventajas comparativas (riqueza de recursos y potencial del campo colombiano) del sector en ventajas competitivas para lograr el objetivo de aumentar el empleo y disminuir la pobreza de la población rural.

La distribución inequitativa de la tierra en Colombia tiene consecuencias y alcances trascendentales, ya que según estándares internacionales, la desigualdad en la tenencia de la tierra es alta ${ }^{5}$, la subutilización de este factor va de la mano con altos niveles de desigualdad, bajo crecimiento, violencia y más inequidad (Banco Mundial, 2004). Sin embargo: "La política de restitución de tierras puede contribuir a romper el círculo vicioso de inequidad y violencia. Para evitar que regiones del país caigan en un ambiente de desigualdad, subutilización de recursos productivos, pobreza y violencia, se requiere de una estrategia multidimensional" (Banco Mundial, 2004, p. 7).

El informe del Banco Mundial (2008) señala que este sector contribuye al desarrollo de tres modos:

- Como actividad económica: crea oportunidades de inversión para el sector privado e impulsa las industrias relacionadas con el sector y con la economía rural no agrícola. Además, al ser considerada fuente de alimentos permite que la población, rural y urbana, tenga acceso a los productos que genera la tierra y de esta manera garantizar la seguridad alimentaria.

- Como medio de subsistencia: a nivel mundial, la agricultura es el medio de trabajo del $86 \%$ del sector rural, por tanto, genera empleo a gran porcentaje de productores y trabajadores sin tierra. Se le atribuye a este sector más del $80 \%$ de responsabilidad en la disminución de la pobreza rural ${ }^{6}$.

$4 \quad$ Las densidades de abandono y despojo se caracterizan, según Restrepo y Bernal (2014) así: alta (78 municipios con 150.806 casos), media (81 municipios con 56.219 casos), baja (256 municipios con 58.502 casos y dispersión (665 municipios con 18.642 casos).

5 Tomando como referencia el avalúo catastral, en lugar del área física, solo reduce el coeficiente de Gini a (0.85) en comparación con países como Japón $(0,38)$ y Corea $(0,35)$, (Banco Mundial, 2008$)$.

6 En Colombia, el $26 \%$ de la población nacional vive en las áreas rurales, de este porcentaje, el $62.1 \%$ (7.351.418 personas) vive en situación de pobreza y el $21.5 \%$ (2.545.177 personas) en pobreza extrema o indigencia; aunque en el área urbana se concentra el mayor número de la población, la condición de pobreza se encuentra en mayor proporción en la rural (Perry, 2010). 
- Como proveedor de servicios ambientales: la utilización de los recursos naturales en la agricultura genera resultados ambientales positivos y negativos: es una actividad económica que consume mucha agua y, por tanto, produce escasez del recurso, pero también reduce la emisión de carbono, ordena las cuencas hidrográficas y preserva la diversidad biológica, entre otros.

Johnston y Mellor (1972) consideran que la agricultura repercute en el crecimiento y desarrollo económico (en términos de producción y productividad), por medio de cinco mecanismos:

a. La demanda sustancial de productos agrícolas es una de las características del desarrollo económico.

b. El aumento de las exportaciones de productos agrícolas es uno de los medios para que aumenten los ingresos y las divisas, especialmente en las primeras etapas del desarrollo.

c. El excedente de la fuerza laboral de la agricultura puede utilizarse para el sector industrial y otros sectores que se encuentren en expansión.

d. La agricultura es, por lo general, el sector dominante de las economías en vías de desarrollo, por tanto, puede contribuir netamente con el capital para el crecimiento de la industria secundaria.

e. El aumento de los ingresos netos de la población agrícola puede estimular el crecimiento del sector industrial.
Para Ramos y Romero (1993), el medio rural es una entidad socioeconómica que se compone de:

a) Un territorio, que es la fuente de recursos naturales y materias primas, receptor de los residuos y el soporte de la actividad económica.

b) Una población, que practica las actividades de producción, consumo y relación social.

c) Un conjunto de asentamientos que mantienen relación entre sí y con el exterior por medio del intercambio de personas, mercancías e información.

d) Un conjunto de instituciones públicas y privadas que conforman el sistema y operan dentro de un determinado marco jurídico.

La visión de la agricultura pasó de estar enfocada en las actividades primarias básicas a una en la que se tienen en cuenta los encadenamientos e interrelaciones ${ }^{7}$ que se establecen a partir de este sector. A ese conjunto de actividades económicas se le denomina sector agroalimentario, complejo agroindustrial o agricultura ampliada (Perfetti \& Cortés, 2013). En el PND (2010-2014), los encadenamientos y la producción de valor son una de las líneas estratégicas para solucionar los cuellos de botella existentes en el sector.

En general, la agricultura históricamente ha desempeñado un rol importante en el desarrollo económico, la evidencia de los países industrializados y emergentes

Procesamiento y transformación industrial, servicios conexos de comercialización y transporte y comercio exterior (Perfetti \& Cortés, 2013). 
ha demostrado que la agricultura ha contribuido en el crecimiento de los sectores no agrícolas y, por tanto, al crecimiento de la producción, ya que puede tener un impacto fuerte en la reducción de la pobreza, el aumento del empleo y los ingresos del sector (Pingali, 2006). "A pesar de este destacable desempeño de la agricultura, es conocido que, desde el punto de vista de las políticas públicas, el sector agropecuario se ha considerado subsidiario al desarrollo de los demás sectores económicos $\mathrm{y}$, en especial, de la industria. Todo esto se ha dado en el marco de la prevalencia de lo urbano sobre lo rural" (Perfetti \& Cortés, 2013, p. 8).

Byerlee, Janvry y Sadoulet (2009) sostienen que se debe cambiar el modo de pensar respecto al rol de la agricultura en el desarrollo, dado que más de 2.5 mil millones de personas en el mundo viven de esta actividad y, por tanto, es importante reconocer que la agenda del desarrollo mundial debería centrarse en el papel de la agricultura para el desarrollo, en lugar de la agricultura en la industrialización; además, dado que el cambio que ha generado la globalización, la adquisición de nuevas tecnologías ${ }^{8}$ y las instituciones del mundo en que opera, el sector ha cambiado drásticamente; es por esto, que ellos consideran que el aporte de la agricultura en el desarrollo está dado por la capacidad que tiene de impulsar el crecimiento económico, reducir la pobreza, proporcionar mayores niveles de equidad (en el sector y de género), mejores condiciones de seguridad alimentaria y sostenibilidad ambiental (Byerlee et al., 2009).

\section{DESEMPEÑO DE LA AGRICULTU- RA Y DESARROLLO RURAL EN COLOMBIA 2011-2013}

En este acápite se presenta una caracterización de la dinámica de la agricultura y el desarrollo rural en Colombia para el periodo 2011-2013. En la primera parte se describe el sector con algunos indicadores, y en la segunda se especifican los avances presentados de acuerdo con las líneas estratégicas propuestas en el PND 2010-2014. Es importante conocer estos aspectos, ya que la situación de la agricultura se ha transformado en los últimos años con una tendencia a la "desagriculturización" del empleo; la migración de la población rural al sector urbano, en parte producto del conflicto armado; la reducción de la rentabilidad de la actividad agrícola, entre otras (Fajardo, 2001).

\section{Caracterización del sector agropecuario en Colombia 2011-2013}

Como ya se describió el papel de la agricultura es fundamental en la

\footnotetext{
8 El cambio técnico ha contribuido a la transformación del sector agrario de manera positiva, sin embargo, según Pingali (2006), en la mayoría de países subdesarrollados el proceso de transformación se encuentra estancado debido a factores como: demanda inelástica y baja en la producción agrícola, poca inversión en las zonas rurales, falta de tecnología e I+D, recursos de tierra limitados y existencia de barreras institucionales que permitan mejorar el crecimiento de la productividad.

$9 \quad$ Las comillas son de Fajardo (2001).
} 
economía, este acápite expone una breve caracterización del sector (en algunos indicadores) en Colombia, para lo cual se tomaron varios aspectos relevantes como son: la producción agropecuaria en el país, el porcentaje de población rural, la tasa de desempleo rural y la tasa de incidencia de la pobreza.

\section{Producción agropecuaria en Colombia}

La Sociedad de Agricultores de Colombia (SAC, 2013) argumenta que la producción agropecuaria, a precios constantes, se recu- peró respecto al año 2010, cuando el PIB agropecuario fue de $0.2 \%$ y para el año 2013 de 6,5\% (ver Figura 1). El Dane registró para el año 2012 un crecimiento de 2.5 $\%$ en el valor de la producción agropecuaria, el cual fue atribuido a la buena dinámica del sector pecuario. Aunque las actividades agrícolas aportaron $1.2 \%$ de este valor, el crecimiento fue menor $(2.1 \%)$ que el del sector pecuario, el cual creció para el año 2012 en $2.9 \%$. La ola invernal, los altos costos de producción y la revaluación son algunos de los factores que impidieron un mayor crecimiento del sector.

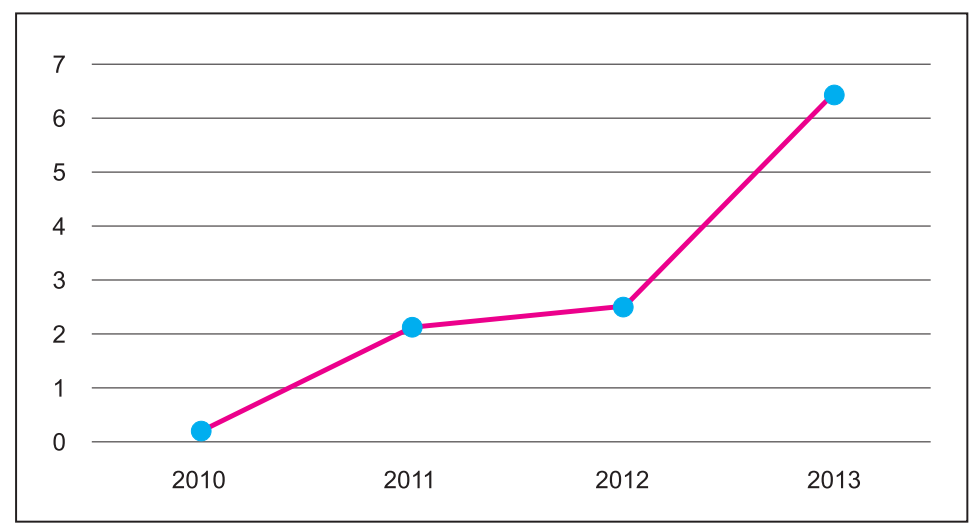

Figura 1. Crecimiento anual del PIB para el sector agropecuario. Fuente: elaboración de los autores con datos tomados del Dane

Según el Informe del Presidente de la República al Congreso (2014), este comportamiento se explica por el crecimiento del valor agregado del cultivo de café de $14.9 \%$ comparado con el primer trimestre de 2013; los demás productos agrícolas presentaron un incremento de $6.5 \%$, y la producción pecuaria y caza de $4.8 \%$.
La participación en el PIB total del sector agropecuario a precios corrientes, a partir de la apertura económica, demuestra una caída que ha sido considerable. Si se compara con la participación que tenía el sector a fines de los años 70, esta se redujo en 2013 a una cuarta parte. Las repercusiones de la mencionada política a lo largo de 
los últimos 23 años han sido significativas, pues mientras en 1990 el crecimiento de la agricultura fue de $5.8 \%$, en 1995 bajó al $1.5 \%$, en el 2001 fue de $8.5 \%$, en el 2010 de 2,3\% y en el 2013 de 3,4\%, es decir, todo el discurso aperturista encaminado a desmontar la estructura arancelaria y paraarancelaria, posibilitando la apertura del comercio internacional y así mismo, a reducir significativamente los mecanismos de promoción y diversificación de las exportaciones, para que sean la modernización y eficiencia de la producción nacional las que garanticen mayor competitividad en los mercados, tanto nacionales como internacionales fracasó. Sin embargo, no han cumplido los objetivos propuestos, sino que, por el contrario, muchos de los problemas actuales (sobre todo en los sectores agrícolas e industrial), tales como bajos niveles de crecimiento y de empleo se deben, en parte, a dicha iniciativa. Sobre el particular, Ocampo (2015) puntualiza:

Hay desigualdad de vieja data que sigue pesando, pero yo diría que además la apertura económica para el sector agropecuario ha sido un fracaso, y no tanto por la apertura misma. Esto es culpa de todos los gobiernos que hemos trabajado en los últimos 25 años en el sector. Yo mismo soy uno de los culpables. Uno mira qué ha pasado desde la apertura y hemos tenido un sector que ha despegado como exportador, la palma africana, y después está en menor escala el azúcar, que ya estaba posicionado antes de la apertura, y algo en frutas, pero muy poco (Ocampo, 2015, p.10).

Por otra parte, el país perdió con la apertura buena parte de la producción agrícola que cubría el mercado interno, y si bien el cambio climático afecta tangencialmente el desabastecimiento de alimentos, las decisiones de política económica aplicadas con la reforma de la apertura, explican por qué en la actualidad el país importa no solo una porción considerable de alimentos de la canasta familiar, sino un segmento considerable de materias primas para la producción de concentrados para animales, si tenemos en cuenta que en la actualidad, según el ministro de Agricultura Aurelio Iragorri (Amat, 2016), se importa: el $100 \%$ de maíz amarillo, el $50 \%$ de fríjol, el $40 \%$ del arroz, el $60 \%$ de las lentejas, el $80 \%$ de arveja seca, el $100 \%$ de trigo, el $40 \%$ del arroz, entre otros bienes.

\section{Tasa de desempleo en el sector rural}

En lo relacionado con el mercado laboral rural en Colombia, se seguirá el documento Misión para la Transformación del Campo (2015). Mercado laboral en el sector rural colombiano, debido a que, sin duda, es el trabajo más importante realizado en Colombia en los últimos años, y se mencionarán los aspectos más relevantes de lo sucedido en el 2013. Mientras que el empleo total en el país se estimaba en 21 millones de personas, el empleo rural era de aproximadamente 6,2 millones de personas, es decir, representó un $29.3 \%$. La agricultura, con $51.1 \%$, es 
el mayor generador de empleo en el sector rural, seguida del comercio, los servicios sociales y la manufactura, con el 17,4\%, $10,6 \%$ y $6,1 \%$, respectivamente.

Si se hace referencia solo a los asalariados, la participación de trabajadores en la agricultura se reduce sustancialmente a un $24.3 \%$, mientras que en el empleo de trabajadores independientes en la agricultura, la proporción es de $48.2 \%$. Lo anterior significa que la mayoría del empleo agrícola es de trabajadores independientes.

Respecto a la posición ocupacional, la forma de trabajo que impera en el sector rural es la de trabajador por cuenta propia o independiente, que representa aproximadamente la mitad del empleo rural (50.1\%). Los sectores con mayor proporción de trabajadores independientes son transporte $(75 \%)$, comercio $(58.6 \%)$, manufactura $(53,7$ $\%)$ y agricultura (50.5\%).
Al analizar la composición del empleo rural de hombres y mujeres, se evidencian diferencias significativas: mientras en los hombres el único sector que genera un monto de empleo notable (fuera de la agricultura) es el comercio (10.5\% del empleo masculino), el fuerte de empleo está por fuera de la agricultura con un $73.7 \%$, y sobresalen el comercio (31.5 $\%$ ) y los servicios sociales $(23.1 \%)$.

El sector agropecuario es el principal generador de empleo en las zonas rurales, es el tercer sector que mayor cantidad de empleo produce en el país, después del sector comercial y de servicios. En 2013 , el $16.9 \%$ de la población ocupada en Colombia trabajó en el mencionado sector (Finagro, 2014). En la Figura 2 se puede ver que la tasa de desempleo en los centros poblados y en el sector rural que registra el Dane fue de $5.5 \%$ en 2011, de $5.3 \%$ en 2012 y en 2013 se presentó una reducción de 0.2 puntos porcentuales con $4.8 \%$.

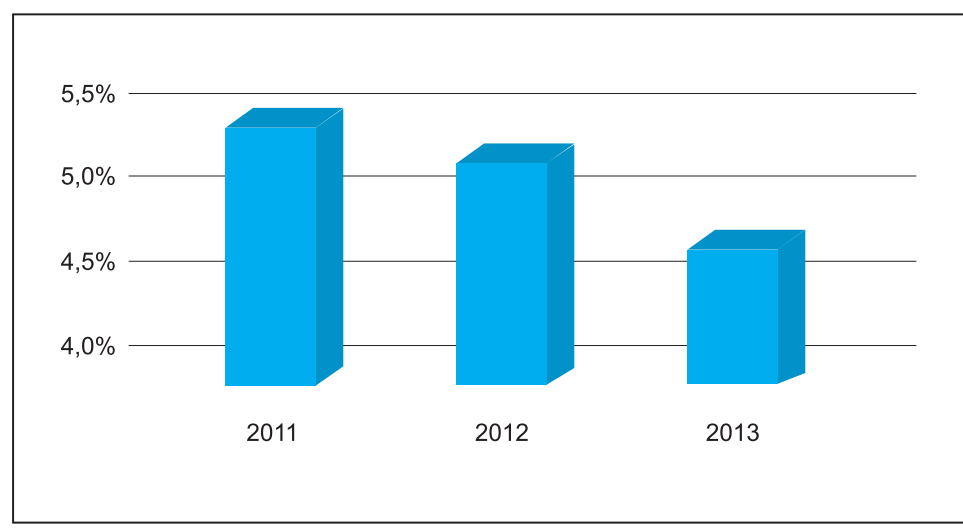

Figura 2. Tasa de desempleo en el sector rural en Colombia 2011-2013. Fuente: elaboración de los autores con datos tomados del Dane 


\section{Tasa de incidencia de la pobreza en el} sector rural

En cuanto al nivel de pobreza en el sector rural, tanto en la categoría unidimensional como multidimensional, se tomó como documento base el trabajo realizado por la Misión para la Transformación del Campo (MTC) del DNP (2014). De hecho, se hará referencia al tema de forma sucinta, con el fin de reseñar los aspectos más relevantes, más que de hacer un análisis exhaustivo. En relación con la primera categoría, y en particular para el último año del periodo de estudio (2013), se observa que en cuanto al sector rural, la Misión detectó que la pobreza por ingresos es mayor para los productores campesinos que para los asalariados del campo, debido a la reducida posibilidad de los primeros de poseer activos productivos (tierra, crédito, tecnología, riego). De dichos activos, los mencionados productores tienen mayor acceso a la tierra (el 36 $\%$ de los hogares rurales), aunque en cantidades insuficientes para obtener un nivel de vida adecuado. La posibilidad de aprovechar otros recursos productivos es relativamente baja.

Como buena parte de los asalariados del campo se emplea en actividades informales de trabajo, esto explica que algunos mecanismos de protección social (el sistema pensional) casi no existen en las zonas rurales, y otros presentan un crecimiento inestable (acceso a los servicios de las cajas de compensación) o se caracterizan por tener una calidad deprimente (educación, salud).
Por otra parte, la pobreza multidimensional en las zonas rurales es notoria (año 2013), sobre todo en educación (analfabetismo, bajo logro educativo y alto rezago escolar), en acceso a agua y saneamiento y en escasez de posibilidades laborales (debido a la elevada informalidad que, como anotábamos, se traduce en el bajo acceso al sistema pensional). En educación, las diferencias de las zonas rurales con la población urbana se manifiestan de la siguiente forma: la población urbana de 15 años y más tiene al menos nueve años de educación obligatoria, la población en las zonas rurales solo tiene primaria completa (5,1 años). Lo más apremiante no es la cobertura (que, como puede observarse, es una carencia notable), sino la pertinencia y la calidad, para que la educación repercuta tanto en mayores ingresos, como en productividad y competitividad.

En lo referente al acceso de servicios de acueducto y alcantarillado, la MTC, fundamentada en la encuesta de calidad de vida del Dane de 2012, encontró que la cobertura en acueducto en la zona rural es del $53 \%$ y en alcantarillado es del $16 \%$, la de la zona urbana es de $97 \%$ y $92 \%$, respectivamente.

En cuanto al servicio de salud, las diferencias de afiliación a la seguridad social entre la zona urbana y la zona rural ya no son tan marcadas, la brecha es considerable en "acceso, uso y calidad de los servicios entre cabeceras y población dispersa y al interior (sic) de las categorías de ruralidad". 
Entre los motivos que explican por qué los habitantes rurales tienen dificultades de acceso, están: las distancias a los centros de salud, los costos de movilización y que la oferta no se ajusta a la estructura demográfica de los hogares rurales (los jóvenes y los adultos participan en forma considerable, mientras que los adultos en edades productivas lo hacen en menor proporción).

Si bien en los últimos diez años la situación de la población rural en lo referente a la pobreza ha mejorado en todos los indicadores, no deja de ser preocupante lo que plantea la MTC:

A pesar de las mejoras, las brechas relativas se han ampliado, y son muy elevadas: la pobreza monetaria extrema era más del triple en las zonas rurales que en las urbanas en 2013 y la pobreza multidimensional 2,5 veces más alta. Otro elemento relacionado es el escaso alcance de la clase media. Según la Misión de movilidad social, solo el $11 \%$ de la población rural podía considerarse como clase media, menos de una tercera parte de dicha proporción en las zonas urbanas (39\%). El $89 \%$ de la población rural es así pobre o vulnerable, es decir con alta probabilidad de caer en pobreza (MTC, 2014, p. 9).

La Figura 3 representa la tasa de incidencia de la pobreza ${ }^{10}$, sobre la base de la línea de pobreza como porcentaje de la población rural. En Colombia, el $46 \%$ de las personas vivían por debajo de la línea de pobreza en 2011 y 2012, y para 2013 la tasa se redujo en $4 \%$. Esto es, en parte, el reflejo del aumento de la productividad del sector y la disminución de la tasa de desempleo registrada por el Dane en este periodo, aunque el porcentaje se redujo, la cifra sigue siendo alta y demuestra las deficiencias de las políticas que aún presenta la población rural.

\footnotetext{
10 "En términos monetarios la pobreza significa la carencia de ingresos suficientes con respecto al umbral de ingreso absoluto, o línea de pobreza, "que corresponde al costo de una canasta de consumo básico" (Romero, 2002, p. 89).
} 


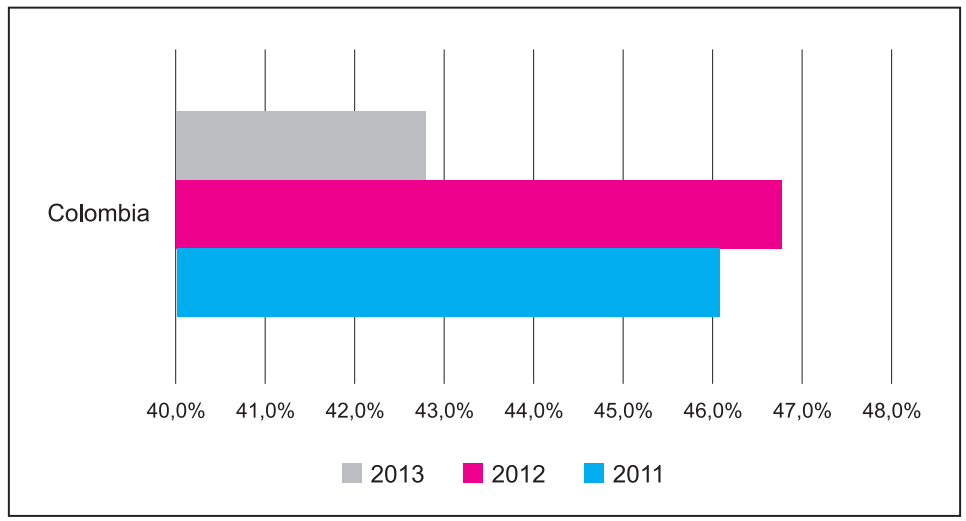

Figura 3. Tasa de incidencia de la pobreza (\% de la población rural) en Colombia. 2011-2013 Fuente: elaboración de los autores con indicadores del desarrollo mundial

(Banco Mundial, 2015).

\section{INDICADORES Y RESULTADO POR LÍNEA ESTRATÉGICA ${ }^{11}$}

La política que propone el Gobierno para solucionar los cuellos de botella que, según el PND 2010-2014, presenta el sector, está formulada en este en las siguientes líneas estratégicas: a) incremento de la competitividad de la producción agropecuaria; b) promoción de los encadenamientos productivos y la agregación de valor; c) ampliación y diversificación de los mercados agropecuarios externos e internos; d) promoción de esquemas de gestión del riesgo y mejoramiento de las condiciones para las inversiones en el campo; e) mejora de la capacidad para generar ingresos por parte de la población rural, f) promoción de la equidad en el desarrollo regional rural; y d) adecuación de la institucionalidad para el desarrollo rural y la competitividad.
En esta sección se presenta una breve descripción de los principales resultados del sector para el periodo 2011-2013, el estudio se basa en los informes al Congreso presentados por la Presidencia de la República y en los resultados publicados por Sinergia:

Línea estratégica $n .^{\circ}$ 1: promover los encadenamientos y la agregación de valor en la producción agropecuaria, forestal y pesquera. Entidad: Ministerio de Agricultura y Desarrollo Rural (ver en el anexo la Tabla 1).

El objetivo para el cuatrienio era otorgar 4.911 créditos y, como se observa en la Tabla 1, al finalizar el año 2013 ya se habían concedido 6623 créditos para comercialización y transformación productiva agropecuaria. En cuanto a los proyectos productivos asociativos,

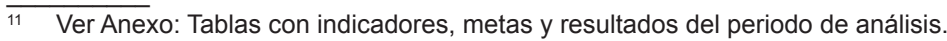


para 2013 se firmaron 218 alianzas de las 180 propuestas para ese año; la meta del periodo eran 641 proyectos.

Respecto al acceso a servicios financieros, en 2012, el Fondo para el Financiamiento del Sector Agropecuario (Finagro) desembolsó un monto de $\$ 2.6$ billones para créditos, incrementando así $18.3 \%$ respecto a 2011. Hubo colocaciones de $\$ 1.7$ billones en 2012, y para mayo de 2013 colocaciones por $\$ 2.54$ billones.

Línea estratégica $n .^{\circ} 2$ : promover los esquemas de gestión de riesgo y mejorar las condiciones para las inversiones en el campo. Entidad: Ministerio de Agricultura y Desarrollo Rural (ver Tabla 2).

De acuerdo con el PND 2010-2014, se esperaba obtener al finalizar el periodo 80.000 hectáreas (ha) de cultivos asegurados, de las cuales a diciembre de 2013 había 68.520 ha, 738 ha más que en 2012. Y en cuanto al sistema de pronóstico y expectativas, hasta 2013 se implementaron cuatro, que era el objetivo trazado por el Gobierno nacional para el cuatrienio.

En la promoción de esquemas de gestión de riesgo y mejoramiento de las condiciones para las inversiones en el campo se han obtenido avances por medio del seguro agropecuario, el cual hasta 2012 había expedido 6.376 pólizas para asegurar 61.104 ha agropecuarias en diferentes cultivos, por un valor de $\$ 312.039$ millones. A mayo de 2013, se habían asegurado 30.343 ha por un valor de \$207.703 millones. Y con el programa de coberturas cambiarias en el año 2012, se protegieron ventas por USD\$ 606.5 millones (tasa de cambio promedio de \$1.902), otorgando así \$33.731,2 como apoyo directo para adquirir cobertura.

Línea estratégica $n .^{\circ}$ 3: promover la equidad en el desarrollo regional rural. Entidad: Ministerio de Agricultura y Desarrollo Rural (ver Tabla 3).

El Gobierno se fijó como meta para el periodo presidencial un total de nueve planes de acción para la definición de conglomerados productivos, pero Sinergia no reporta datos al respecto. Para 2013, el plan integral de altillanura había avanzado un $50 \%$, el objetivo es terminar el plan al terminar el cuatrienio.

Línea estratégica $n .^{\circ}$ 4: incrementar la competitividad de la producción agropecuaria. Entidad: Instituto Colombiano de Desarrollo Rural (ver Tabla 4).

En este programa se renovaron, hasta 2013, 15 paquetes tecnológicos de los 20 propuestos en el PND 2010-2014 para el periodo; se adecuaron 163.722 ha con riego y drenaje Incoder para el año 2013, 1701 ha más que en 2012; se liberaron 23 nuevas variedades de las 26 propuestas para todo el periodo presidencial. Referente a los créditos para la comercialización y transformación productiva agropecuaria, se otorgaron 6.961.237 millones de pesos por parte 
de Finagro hasta diciembre de 2013, esta misma entidad colocó 1.657 .981 millones de pesos para siembra de cultivos.

Para cumplir el objetivo de mejorar la competitividad del sector agropecuario, el Gobierno nacional ha venido promoviendo por medio del Instituto Colombiano Agropecuario (ICA) la siembra de cultivos de semilla certificada. Al finalizar 2012 se habían sembrado 761.714 ha de cultivos entre arroz, maíz, fríjol y soya, y a mayo de 2013 el área sembrada ascendió 337.280 ha. Así mismo, a través de convenios con el Ministerio de Agricultura y la Corporación Colombiana de Investigación Agropecuaria (Corpoica), se generaron once paquetes tecnológicos que contribuyen a mejorar la competitividad en el sector.

Por medio del programa Desarrollo Rural con Equidad ${ }^{12}(\mathrm{DRE})^{13}$, se completaron las pruebas hidráulicas para 31 de 33 proyectos con financiación y fueron entregados a los habitantes un total de 14.566 ha con riego y drenaje. Por otra parte, el Instituto Colombiano de Desarrollo Rural (Incoder) para 42.761 ha continuó desarrollando la infraestructura para los distritos de riego del río Ranchería, el Triángulo del Tolima y Tesalia Paicol.

El programa DRE informó acerca de 576.536 beneficiarios en diferentes campos de asistencia técnica integral, de los cuales, 403.762 productores fueron atendidos en alianza con la Federación Nacional de Cafeteros. Y hasta mayo de 2013, 22.405 pequeños productores en condiciones vulnerables fueron atendidos a través de Servicio de Asistencia Técnica Especial.

Línea estratégica $n .^{\circ}$ : mejorar la capacidad para generar ingresos por parte de la población rural. Entidad: Instituto Colombiano de Desarrollo Rural (ver Tabla 5).

La política integral de tierras benefició hasta 2013 a 394 familias con el subsidio integral de tierras en municipios de consolidación ${ }^{14}$ de las 300 propuestas para ese año; en el año 2013 no se registró ninguna familia afrodescendiente beneficiada con la titulación colectiva, pero para 2011 y 2013 se favorecieron 3.098 y 4.904 familias, respectivamente. Según Sinergia, el $100 \%$ de las víctimas contaba con representación legal ante la

\footnotetext{
12 El Programa Agro Ingreso Seguro, ahora denominado Desarrollo Rural con Equidad -DRE-, creado por la Ley 1133 de 2007, tiene como objetivos fundamentales mejorar la competitividad y productividad del sector agropecuario y contribuir a reducir las desigualdades en el campo (Ministerio de Agricultura y Desarrollo Rural, 2015).

13 Referente al programa DRE, Restrepo y Bernal afirman que: "Nunca en la historia del desarrollo rural en Colombia se había logrado un resultado como este, que fue posible... por la transformación del AIS en DRE, durante los primeros tiempos de la administración Santos" (Restrepo \& Bernal, 2014, p. 155).

14 Los municipios en consolidación son territorios que cuentan con un gran valor ambiental y estratégico, además, con un alto potencial de desarrollo social y económico, y se encuentran ubicados en zonas que han sido afectadas por el conflicto armado y los cultivos ilícitos (Unidad Administrativa para la Consolidación Territorial -UACT-, 2015).
} 
Unidad de Restitución de Tierras (URT) en 2013.

En cuanto a las soluciones de vivienda, el Gobierno se fijó una meta de 11.850 para 2011, 2012 y 2013 para pobladores rurales pobres, la cual superó las expectativas al entregar 29.932, 12.583 y 14.778 casas, respectivamente. Las familias desplazadas también se vieron favorecidas con este programa, dado que 4.521 familias recibieron solución de vivienda en 2013.

Con el programa de asistencia técnica en municipios de consolidación, para 2013 se beneficiaron 22.076 pequeños productores, 329 menos que los propuestos para este año. Así mismo, se establecieron 63 organizaciones del programa de oportunidades rurales en los municipios de consolidación y se instalaron 22 oficinas territoriales.

En 2012 se implementó el Programa de Formalización de la Propiedad Rural, con el cual más de 18.000 familias han entregado documentos de tierras, privilegiando 27 municipios, de los cuales 14 son de la zona cafetera. Por otra parte, el Incoder, en lo corrido del periodo, adjudicó 2.000.000 ha para favorecer a familias campesinas, afrodescendientes e indígenas, con el objetivo de constituir y ampliar resguardos. Por medio del programa de Vivienda de Interés Social Rural (VISR), el Gobierno nacional entregó, hasta ese momento, 37113 viviendas (de las 100.000 viviendas gratis con las que se ha comprometido el Gobierno).
Línea estratégica $n .^{\circ}$ 6: ampliar y diversificar el mercado interno y externo con productos de calidad. Entidad: Instituto Colombiano Agropecuario (ver Tabla 6).

Los protocolos de exportación superaron las expectativas, ya que de $\operatorname{los} 40$ propuestos para el cuatrienio, para el año 2013 ya se habían firmado 142 . Se registran 20 zonas libres de plagas (meta para el periodo de 27) y enfermedades establecidas y 8 zonas de baja prevalencia establecidas (meta para el periodo de 11) al finalizar el año 2013.

Con el objetivo de mejorar la diversificación y ampliación de los mercados agropecuarios externos e internos con productos de calidad, a través del ICA se firmaron, hasta mayo de 2013, 28 protocolos de exportación (15 pecuarios y 13 agrícolas), que permitieron la entrada de productos colombianos a 15 países, entre ellos: Venezuela, Rusia, Estados Unidos, Chile, China, Jordania, entre otros. Respecto a la sanidad de los productos agropecuarios, durante el periodo se mantuvieron ocho zonas del país libres de plagas y enfermedades comunes en el sector, además, fue incorporada la región del Valle de Sibunday (Putumayo) como zona libre de brucelosis bovina.

\section{CONCLUSIONES}

Las políticas dirigidas al campo colombiano se enmarcan en los planes de desarrollo implementadas a nivel nacional. Y dichos planes, de una u otra forma, han 
estado ajustados a las teorías económicas prevalecientes en cada momento. Pero, generalizando, se puede sostener que a lo largo de la planeación en Colombia ha habido dos orientaciones básicas: la escuela cepalina (con su influencia keynesiana) y los planteamientos neoliberales. En el caso del sector rural en Colombia, en los sesenta se intentó un proceso de reforma agraria. Esta iniciativa no obedeció a un pleno convencimiento de la dirigencia colombiana de que uno de los problemas centrales que ha tenido el campo colombiano es la concentración de la tierra, sino, más bien, que la Cepal, para la mencionada época, planteaba que en aquellas regiones donde hubiese problemas de tenencia de la tierra era necesario que se diera un proceso de reforma agraria, ya que esta escuela argumentaba que si existían problema estructurales, la única solución eran reformas de la misma índole.

Posteriormente, en los primeros cuatro años de los setenta, en la administración de Pastrana Borrero, y teniendo en cuenta que quien orientó el Plan de las Cuatro Estrategias fue Lauchlin Currie, para quien el problema del campo colombiano no era la tenencia de la tierra, sino la mejora de las condiciones de producción y productividad del campo, se descartó, por lo tanto, la propuesta de reforma agraria.

Por otra parte, en el modelo neoliberal, la principal propuesta para el campo es el programa de Desarrollo Rural Integrado DRI, creado en 1975, orientado a incen- tivar la producción y la productividad en el sector agrícola, sobre todo en las zonas de minifundio; pero, para el mismo año, se divulga la Ley $6 .^{\text {a }}$, que fortalece el desarrollo de la agricultura por medio de la gran propiedad y margina completamente los problemas de tierras como elemento preocupante de la política agraria.

Se evidencia que la política agraria en Colombia debe ser abordada bajo la perspectiva de la nueva visón del desarrollo rural, en la cual deben incluirse actividades que desarrollen dicha área, y el gran reto debe ser replantear el hecho de que el sector rural no solamente se limita al sector productivo. Este nuevo enfoque obliga al Gobierno nacional a revisar las políticas de desarrollo rural tendientes a abarcar los aspectos no solo económicos, sino también políticos, sociales y culturales que afectan a las gentes del campo.

Las conversaciones de paz son fundamentales para el logro de la estrategia que propone mejorar la capacidad para generar ingresos por parte de la población rural, ya que permiten no solo avanzar en el proceso de restitución de tierras, el cual facilita el regreso de los campesinos a sus predios, sino también unas serie de estrategias en cuanto a financiamiento, asistencia técnica, mercadeo, vivienda rural de interés social, esquema de riego y drenaje, y en general, todo aquello que efectivamente contribuya a elevar la producción y productividad del campo. De este modo, las políticas que propone el Gobierno para el campo pueden generar 
una verdadera equidad en el desarrollo rural, que se ha visto entorpecida por la violencia que vive el país hace más de cincuenta años.

Se demostró, de acuerdo con indicadores, metas y resultados del PND 2010-2014, que el sector avanzó en gran parte de las líneas estratégicas propuestas, sin embargo, la estrategia que menos refleja resultados es la de promover la equidad en el desarrollo regional rural, la cual establece el logro de algunos conglomerados productivos y el Plan Integral Altillanura. Vale afirmar que la ejecución de estos proyectos permitirá la generación de empleo en varios sectores de la economía, lo que, a su vez, contribuirá en la reducción de la pobreza, y por ende, en el desarrollo rural con equidad.

\section{REFERENCIAS}

Amat, Y. (2016, 7 feb.). Supermercados, culpables del alto precio de alimentos: Minagricultura. El Tiempo. Recuperado de http://www.eltiempo.com/ economia/sectores/aurelio-iragorri-pide-a-superindustria-verificar-precio-dealimentos/16502957

Balcázar, A. (1985). Marco histórico para el análisis de la política agraria. Revista Cuadernos de Economía, Universidad Nacional, (5).

Banco Mundial. (2004). Colombia: una política de tierras en transición, Documentos Cede, Universidad de los Andes, (29).

Banco Mundial. (2008). Informe sobre el desarrollo mundial 2008. Agricultura para el desarrollo. Bogotá: Banco Mundial, Mundi-Prensa y Mayol.

Bejarano, J. (1982). Industrialización y política económica 1950-1976. En M. Arrubla et al. Colombia Hoy. (8 ed.).Bogotá: Siglo XXI.

Bejarano, J. (1998). Economía de la agricultura. Bogotá: TM Editores, Universidad Nacional, Facultad de Ciencias Económicas, IICA, FONADE.

Bejarano, J. (1998a). El concepto de lo rural: ¿Qué hay de nuevo? Revista Nacional de Agricultura, Números., 922 -923.

Byerlee, D., De Janvry, A. \& Sadoulet, E. (2009). Agriculture for Development: Toward a New Paradigm. Retrieved from http://gspp.berkeley.edu/assets/uploads/ research/pdf/Annual_Review_of_ResEcon7.pdf 
Cardona, M. Barrero, Y., Gaviria, C. Álvarez, E. \& Muñoz, J C. (2007). Aportes teóricos del debate de la agricultura desde la economía. Borradores Departamento de Economía, Universidad de Antioquia, (27).

Ceña, F. (1993). El desarrollo rural en sentido amplio. En R. Ramos, E. y P. Caldente y del Pozo. El desarrollo rural andaluz a las puertas del siglo XXI. Congresos y Jornadas 32/93. Andalucía, España: Dirección General de Investigación, Tecnología y Formación Agroalimentaria y Pesquera, Consejería de Agricultura y Pesca, Junta de Andalucía.

Departamento Nacional de Planeación -DNP-. (1972). Plan Nacional de Desarrollo: Las cuatro estrategias. Bogotá: DNP.

Departamento Nacional de Planeación -DNP-. (1991). Plan Nacional de Desarrollo: La revolución pacífica. Bogotá: DNP.

Departamento Nacional de Planeación -DNP-. (2010). Bases del Plan Nacional de Desarrollo 2010-2014, Prosperidad para todos. Bogotá: DNP.

Departamento Nacional de Planeación -DNP-. (2010). Plan Nacional de Desarrollo 2010-2014, Prosperidad para todos. Tomo I. Bogotá: DNP.

Departamento Nacional de Planeación-DNP-. (2014). Misión para la Transformación del Campo (MTC). Bogotá: DNP.

Fajardo, D. (2001). La tierra y el poder politico; la reforma agraria y la reforma rural en Colombia. Recuperado de http:/www.fao.org/docrep/004/y3568t/ y3568t02.htm

Finagro. (2014). Perspectiva del sector agropecuario colombiano. Fondo para el Financiamiento del Sector Agropecuario. Bogotá: Finagro.

Informe al Congreso. (2014). Informe al Congreso Juan Manuel Santos. Presidencia. Secretaria de Prensa República de Colombia. Recuperado de: http://wsp. presidencia.gov.co/Publicaciones/Documents/InformePresidente2014.pdf

Hernández, A. \& Becerra, A. (2013). Capital básico para la agricultura colombiana. En Politicas para el desarrollo de la agricultura en Colombia. Bogotá: Sociedad de Agricultores Colombianos SAC, Fedesarrollo, La Imprenta Editores.

Organización de las Naciones Unidas. (2015). Objetivos del desarrollo del milenio. Recuperado de http://www.un.org/es/millenniumgoals/pdf/2015/mdgreport-2015_spanish.pdf 
Jaramillo, C., Perfetti, J. \& Ramírez, J. (1991). Modelos de desarrollo, sector agropecuario y desarrollo rural: hacia un nuevo paradigma. En A. Machado (comp.). Desarrollo rural y apertura económica. Bogotá: Fondo DRI Ministerio de Agricultura e IICA (Oficina en Colombia).

Junguito, R., Perfeti, J. \& Becerra, A. (2014). Desarrollo de la agricultura colombiana. Cuadernos de Fedesarrollo, (48).

Kalmanovitz, S. \& López, E. (2006). La agricultura colombiana en el siglo XX. Bogotá: Fondo de Cultura Económica y Banco de la República.

Leibovich, J. \& Estrada, L. (2008) Competitividad del sector agropecuario colombiano basado en el estudio: diagnóstico y recomendaciones de política para mejorar la competitividad del sector agropecuario colombiano. Consejo Privado de Competitividad. Recuperado de: http:/www.compite.com.co/site/wp-content/ uploads/informes/2008-2009/Agropecuario-(agricultura).pdf

Leibovich, J. Nigrinis, M. \& Ramos, M. (2006). Caracterización del mercado laboral rural en Colombia. Revista Banco de la República, (408).

Machado, A. (Comp.). (1991). Las politicas neoliberales y el desarrollo rural. Desarrollo rural y apertura económica. Bogotá: Fondo DRI (Ministerio de Agricultura) e IICA (oficina en Colombia).

Machado, A. (2002). De la estructura agraria al sistema agroindustrial. Bogotá: Universidad Nacional de Colombia.

Mellor, J. \& Johnston, B. (1972). El papel de la agricultura en el desarrollo económico. Lecturas sobre desarrollo agrícola. Selección de Edmundo Flores. México: Fondo de Cultura Económica.

Misión para la Transformación del Campo. (2015). Mercado laboral en el sector rural colombiano. Bogotá: s.n.

Pérez, E. (1998). Una visión del desarrollo rural en Colombia. Cuadernos de Desarrollo Rural, (41).

Perfetti, J. \& Cortés, S. (2013). La agricultura y el desarrollo de los territorios rurales. En Políticas para el desarrollo de la agricultura en Colombia. Bogotá: Sociedad de Agricultores Colombianos -SAC- Fedesarrollo, La Imprenta Editores.

Perry, S. (2010). La pobreza rural en Colombia. Chile: Centro Latinoamericano para el Desarrollo Rural RIMISP. 
Pingali, P. (2006, August). Agricultural growth and economic development: a view through the globalization lens. In Presidential Address to the 26th International Conference of Agricultural Economists, Gold Coast, Australia.

PNUD. (2011, sep.). Colombia rural. Razones para la esperanza. Informe Nacional de Desarrollo Humano 2011. Bogotá: INDH PNUD.

Ramos, E. \& Romero, J. J. (1993). La crisis del modelo de crecimiento y las nuevas funciones del medio rural. En El Desarrollo Rural Andaluz a las Puertas del siglo XXI. Congresos y Jornadas, Andalucía, España.

Reforma Rural Integral. (2014). Hacia un nuevo campo colombiano. Borrador conjunto entre los delegados del Gobierno de la República de Colombia y las Fuerzas Armadas Revolucionarias de Colombia (FARC-EP), La Habana, Cuba.

Restrepo, J.C. (2011). Política integral de tierras: sector agropecuario locomotora de crecimiento. La política comercial del sector agrícola en Colombia. Cuadernos Fedesarrollo, (38), 11-22. Recuperado de http://www.fedesarrollo.org.co/wpcontent/ uploads/ 2011/ 08/ Cuaderno-No-38_web1.pdf

Restrepo, J.C. \& Bernal, A. (2014). La cuestión agraria. Tierra y posconflicto en Colombia. Bogotá: Penguin Random House.

Reynolds, L. G. (1975). Agriculture in development theory, an overview. In Reynolds (ed.), Agriculture in development theory. New Haven: Yale University Press.

Rhenals, R. (2011). Las locomotoras del Plan: unas breves observaciones. Revista Economía y Desarrollo, 10(1), 121-126.

Rodríguez, O. (1981). La teoría del subdesarrollo de la CEPAL. México: Siglo XXI.

Romero, A. (2002). Globalización y pobreza. Pasto, Nariño, Colombia: Universidad de Nariño, Editorial Universitaria.

Sarmiento, E. (2014, 04, oct.). La negociación agrícola. Periódico El Espectador. Recuperado de: http://www.elespectador.com/opinion/negociacion-agricolacolumna-520516

Sarmiento, E. (2014, 01, marzo). Subsidios a la agricultura. Periódico El Espectador. Recuperado de: http://www.elespectador.com/opinion/subsidios-agriculturacolumna-477963

Schultz, T.W. (1968). Modernización de la agricultura. Madrid: Editorial Aguilar de Ediciones Juan Bravo. 
Sepúlveda, A. Rodríguez, A. Echeverri, R. \& Portilla, M. (2003). El enfoque territorial del desarrollo rural. San José de Costa Rica: Dirección de Desarrollo Rural Sostenible, Instituto Interamericano de Cooperación para la Agricultura IICA.

Sociedad de Agricultores de Colombia SAC. (2013). Balance y perspectivas del sector agropecuario 2012-2013. Recuperado de http://www.sac.org.co/es/estudioseconomicos/balance-sectoragropecuario-colombiano.html

Trivelli, C. (2005). Estrategias y políticas de desarrollo rural. Revista Economía y Sociedad, (57). Recuperado de http://old.cies.org.pe/files/ES/bol\%20 57/01-trivelli.pdf

Trivelli, C., Escobal, J. \& Revesz, B, (2009). Desarrollo rural en la Sierra. Aportes para el debate. IEP. CIPCA. GRADE. CIES. Recuperado de http://www.grade. org.pe/download/pubs/libros./Desarrollo.pdf

Universidad Nacional de Colombia. (2012). Análisis socioeconómico de los dos primeros años del gobierno Santos. Recuperado de http://www.cid.unal.edu. co/cidnews/index.php/noticias/2107-santos2.html

Vergara, W. (2011). Reforma agraria en Colombia y "Prosperidad para Todos": ¿el camino hacia el desarrollo humano? Revista de la Universidad de la Salle, (54), 88-109. 


\section{Anexo}

Tabla 1. Indicadores, metas y resultados línea estratégica $n .^{\circ} 1$

\begin{tabular}{|c|c|c|c|c|c|c|}
\hline \multirow{2}{*}{ Indicador/Año } & \multicolumn{2}{|c|}{2011} & \multicolumn{2}{c|}{2012} & \multicolumn{2}{c|}{2013} \\
\cline { 2 - 7 } & Meta & Resultado & Meta & Resultado & Meta & Resultado \\
\hline $\begin{array}{l}\text { Créditos otorgados } \\
\text { para comercialización }\end{array}$ & 1.057 & 3.611 & 2.221 & 4.935 & 3.501 & 6.623 \\
$\begin{array}{l}\text { y transformación pro- } \\
\text { ductiva agropecuaria }\end{array}$ & 108 & 127 & 182 & 188 & 180 & 218 \\
\hline $\begin{array}{l}\text { Proyectos productivos } \\
\text { asociativos }\end{array}$ & & & & & & \\
\hline
\end{tabular}

Fuente: elaboración de los autores con datos tomados del Sistema Nacional de Evaluación de Gestión y Resultados (SINERGIA).

Tabla 2. Indicadores, metas y resultados línea estratégica $n .^{\circ} 2$

\begin{tabular}{|l|c|c|c|c|c|c|}
\hline \multirow{2}{*}{ Indicador/Año } & \multicolumn{2}{|c|}{2011} & \multicolumn{2}{c|}{2012} & \multicolumn{2}{c|}{2013} \\
\cline { 2 - 7 } & Meta & Resultado & Meta & Resultado & Meta & Resultado \\
\hline $\begin{array}{l}\text { Hectáreas con seguro } \\
\text { agropecuario }\end{array}$ & 50.000 & 56.599 & 60.000 & 61.104 .27 & 70.000 & 68.520 \\
\hline $\begin{array}{l}\text { Productos implemen- } \\
\text { tados en el sistema de } \\
\text { pronóstico y expec- } \\
\text { tativas }\end{array}$ & - & 00 & 1 & 1 & 2 & 4 \\
\hline
\end{tabular}

Fuente: elaboración de los autores con datos tomados del Sistema Nacional de Evaluación de Gestión y Resultados (SINERGIA).

Tabla 3. Indicadores, metas y resultados línea estratégica n. ${ }^{\circ} 3$

\begin{tabular}{|l|c|c|c|c|c|c|}
\hline \multirow{2}{*}{ Indicador/Año } & \multicolumn{2}{|c|}{2011} & \multicolumn{2}{c|}{2012} & \multicolumn{2}{c|}{2013} \\
\cline { 2 - 7 } & Meta & Resultado & Meta & Resultado & Meta & Resultado \\
\hline $\begin{array}{l}\text { Conglomerados } \\
\text { productivos } \\
\text { desarrollados }\end{array}$ & 0 & - & 3 & - & 6 & - \\
\hline $\begin{array}{l}\text { Avance en el plan } \\
\text { integral Altillanura }\end{array}$ & 50 & 50 & 100 & - & - & - \\
\hline
\end{tabular}

Fuente: elaboración de los autores con datos tomados del Sistema Nacional de Evaluación de Gestión y Resultados (SINERGIA). 
Agricultura y desarrollo rural en Colombia 2011-2013: una aproximación Johanna Inés Cárdenas Pinzón - Luis Eudoro Vallejo Zamudio

Tabla 4. Indicadores, metas y resultados línea estratégica n. ${ }^{\circ} 4$

\begin{tabular}{|c|c|c|c|c|c|c|}
\hline \multirow[t]{2}{*}{ Indicador/Año } & \multicolumn{2}{|c|}{2011} & \multicolumn{2}{|c|}{2012} & \multicolumn{2}{|c|}{2013} \\
\hline & Meta & Resultado & Meta & Resultado & Meta & Resultado \\
\hline $\begin{array}{l}\text { Colocaciones créditos de } \\
\text { FINAGRO (millones de } \\
\text { pesos) }\end{array}$ & 4.100 .000 & 5.473 .100 & 6.000 .000 & 6.472 .143 & 6.600 .000 & 6.961 .237 \\
\hline $\begin{array}{l}\text { Hectáreas con riego y } \\
\text { drenaje INCODER }\end{array}$ & - & - & 162.021 & 1.721 & 163.733 & 163.722 \\
\hline $\begin{array}{l}\text { Productores vinculados a la } \\
\text { estrategia CeluAgronet }\end{array}$ & 140.000 & 142.166 & 180.000 & 180.127 & 250.000 & 251.639 \\
\hline $\begin{array}{l}\text { Paquetes tecnológicos } \\
\text { disponibles }\end{array}$ & 5 & 5 & 10 & 5 & 15 & 15 \\
\hline $\begin{array}{l}\text { Hectáreas con riego y } \\
\text { drenaje DRE }\end{array}$ & - & - & 16.400 & 13.438 & 39.900 & 15.942 \\
\hline $\begin{array}{l}\text { Total hectáreas con riego y } \\
\text { drenaje }\end{array}$ & 0 & 0 & 178.421 & 15.150 & 203.633 & 179.664 \\
\hline $\begin{array}{l}\text { Nuevas variedades libe- } \\
\text { radas comercialmente }\end{array}$ & 26 & 23 & 31 & 23 & 39 & 23 \\
\hline $\begin{array}{l}\text { Hectáreas agrícolas sem- } \\
\text { bradas sin forestales }\end{array}$ & 4.535 .039 & 4.675 .950 & 4.633 .166 & 4.868 .666 & 4.751 .401 & 5.007 .925 \\
\hline $\begin{array}{l}\text { Hectáreas productivas } \\
\text { agrícolas }\end{array}$ & 4.045 .154 & 3.964 .731 & 4.145 .236 & 4.062 .257 & 4.227 .733 & 4.269 .399 \\
\hline $\begin{array}{l}\text { Hectáreas sembradas en } \\
\text { cultivos transitorios }\end{array}$ & 1.555 .869 & 1.637 .988 & 1.592 .653 & 1.705 .988 & 1.613 .448 & 1.748 .194 \\
\hline $\begin{array}{l}\text { Toneladas de producción } \\
\text { agrícola sin forestales }\end{array}$ & 24.935 .349 & 24.139 .909 & 25.965 .964 & 24.984 .561 & 27.076 .056 & 26.785 .204 \\
\hline $\begin{array}{l}\text { Hectáreas sembradas con } \\
\text { semilla certificada }\end{array}$ & 584.643 & 631.251 & 613.875 & 761.714 & 644.569 & 726.644 \\
\hline $\begin{array}{l}\text { Toneladas de producción } \\
\text { pecuaria }\end{array}$ & 3.653 .463 & 3.620 .221 & 3.719 .351 & 3.741 .171 & 3.786 .733 & 3.939 .090 \\
\hline $\begin{array}{l}\text { Toneladas de producción } \\
\text { acuícola (piscicultura y } \\
\text { camarones) }\end{array}$ & 85.275 & 82.622 & 89.458 & 89.509 & 93.847 & 93.024 \\
\hline $\begin{array}{l}\text { Toneladas de producción } \\
\text { ganadería bovina }\end{array}$ & 1.690 .917 & 1.606 .503 & 1.711 .660 & 1.664 .553 & 1.732 .674 & 1.696 .746 \\
\hline $\begin{array}{l}\text { Productividad agrícola } \\
\text { (toneladas/hectárea) }\end{array}$ & 6.16 & 6.10 & 6.26 & 6.20 & 6.40 & 6.30 \\
\hline $\begin{array}{l}\text { Colocaciones crédito Fina- } \\
\text { gro otorgado para siembra } \\
\text { de cultivos (millones de } \\
\text { pesos) }\end{array}$ & - & 1.658 .232 & - & 1.699 .797 & - & 1.657 .981 \\
\hline $\begin{array}{l}\text { Inversión establecimiento } \\
\text { de cultivos de tardío ren- } \\
\text { dimiento jalonado con el } \\
\text { ICR (millones de pesos) }\end{array}$ & - & 456.394 & - & 573.283 & - & 667.395 \\
\hline $\begin{array}{l}\text { Recursos CIF para esta- } \\
\text { blecimiento por desem- } \\
\text { bolsar (millones de pesos) }\end{array}$ & 15.300 & 15.300 & 100.000 & 51.069 & 100.800 & 41.738 \\
\hline $\begin{array}{l}\text { Hectáreas forestales a } \\
\text { establecer CIF }\end{array}$ & 12.100 & 13.169 .9 & 55.000 & 56.939 .11 & 80.000 & 23.949 \\
\hline $\begin{array}{l}\text { Hectáreas sembradas en } \\
\text { cultivos permanentes }\end{array}$ & 2.988 .061 & 3.037 .961 & 3.050 .250 & 3.162 .679 & 3.128 .616 & 3.259 .731 \\
\hline
\end{tabular}

Fuente: elaboración de los autores con datos tomados del Sistema Nacional de Evaluación de Gestión y Resultados (SINERGIA). 
Tabla 5. Indicadores, metas y resultados línea estratégica n. ${ }^{\circ} 5$

\begin{tabular}{|c|c|c|c|c|c|c|}
\hline \multirow[t]{2}{*}{ Indicador/Año } & \multicolumn{2}{|c|}{2011} & \multicolumn{2}{|c|}{2012} & \multicolumn{2}{|c|}{2013} \\
\hline & Meta & Resultado & Meta & Resultado & Meta & Resultado \\
\hline $\begin{array}{l}\text { Actos administrativos de } \\
\text { registro ante la unidad de } \\
\text { restitución de tierras en los } \\
\text { municipios de consolida- } \\
\text { ción }\end{array}$ & - & - & - & - & 40 & 74.7 \\
\hline $\begin{array}{l}\text { Actos administrativos de } \\
\text { registro ante la unidad de } \\
\text { restitución de tierras }\end{array}$ & - & - & 70 & 55 & 80 & 71.7 \\
\hline $\begin{array}{l}\text { Actos administrativos de } \\
\text { registro ante la unidad de } \\
\text { restitución de tierras para } \\
\text { mujeres }\end{array}$ & - & - & 70 & 63 & 80 & 62.7 \\
\hline $\begin{array}{l}\text { Estudio de sustracción de } \\
\text { reservas forestal en zonas } \\
\text { de consolidación }\end{array}$ & 0 & - & 2 & - & 1 & - \\
\hline $\begin{array}{l}\text { Familias beneficiadas con } \\
\text { proyectos de desarrollo } \\
\text { rural en municipios de } \\
\text { consolidación }\end{array}$ & 0 & - & 579 & 583 & 1.178 & 314 \\
\hline $\begin{array}{l}\text { Familias beneficiadas con } \\
\text { proyectos de desarrollo } \\
\text { rural INCODER }\end{array}$ & - & - & - & - & 2.000 & 2.263 \\
\hline $\begin{array}{l}\text { Familias beneficiadas con } \\
\text { subsidio integral de tierras } \\
\text { en municipios de consoli- } \\
\text { dación }\end{array}$ & 146 & 151 & 95 & 98 & 300 & 394 \\
\hline $\begin{array}{l}\text { Familias beneficiadas titu- } \\
\text { lación baldíos + FNA }\end{array}$ & 21.364 & 13.282 & 21.100 & 16.076 & 15.300 & 9.338 \\
\hline $\begin{array}{l}\text { Familias beneficiadas } \\
\text { titulación baldíos + FNA } \\
\text { en municipios de consoli- } \\
\text { dación }\end{array}$ & 2.586 & 2.572 & 3.864 & 3.888 & 3.550 & 1.662 \\
\hline $\begin{array}{l}\text { Familias beneficiadas titu- } \\
\text { lación colectiva comunida- } \\
\text { des afrodescendientes }\end{array}$ & 3.098 & 3.098 & 3.000 & 4.904 & 3.000 & 0 \\
\hline $\begin{array}{l}\text { Familias beneficiadas titula- } \\
\text { ción resguardos indígenas }\end{array}$ & 1.990 & 1.990 & 3.500 & 1.266 & 3.500 & 966 \\
\hline $\begin{array}{l}\text { Hectáreas definidas en las } \\
\text { sentencias }\end{array}$ & - & - & - & 165 & - & 19.135 .59 \\
\hline $\begin{array}{l}\text { Hectáreas en las solicitudes } \\
\text { en acto administrativo de } \\
\text { inclusión en el RTDA }\end{array}$ & - & - & - & 115.652 & - & 211.298.08 \\
\hline $\begin{array}{l}\text { Hectáreas identificadas en } \\
\text { las solicitudes de restitu- } \\
\text { ción pendientes del fallo } \\
\text { judicial }\end{array}$ & - & - & - & - & - & 154.856 .6 \\
\hline
\end{tabular}




\begin{tabular}{|c|c|c|c|c|c|c|}
\hline \multirow{2}{*}{ Indicador/Año } & \multicolumn{2}{|c|}{2011} & \multicolumn{2}{|c|}{2012} & \multicolumn{2}{|c|}{2013} \\
\hline & Meta & Resultado & Meta & Resultado & Meta & Resultado \\
\hline $\begin{array}{l}\text { Hectáreas tituladas comuni- } \\
\text { dades afrodescendientes }\end{array}$ & 80.401 & 80.401 .22 & 106.533 & 98.1803 & 106.533 & 0 \\
\hline \begin{tabular}{l|l} 
Oficinas territoriales \\
instaladas
\end{tabular} & 0 & - & 17 & 11 & 20 & 22 \\
\hline $\begin{array}{l}\text { Organizaciones de pro- } \\
\text { ductores por el programa } \\
\text { oportunidades rurales en } \\
\text { los municipios de conso- } \\
\text { lidación }\end{array}$ & 13 & 13 & 23 & 23 & 35 & 63 \\
\hline $\begin{array}{l}\text { Pequeños productores be- } \\
\text { neficiados con el programa } \\
\text { de asistencia técnica en mu- } \\
\text { nicipios de consolidación }\end{array}$ & - & - & - & - & 22.405 & 22.076 \\
\hline $\begin{array}{l}\text { Porcentaje de compensacio- } \\
\text { nes pagadas por el fondo de } \\
\text { restitución }\end{array}$ & - & - & 60 & 0 & 70 & 33.3 \\
\hline $\begin{array}{l}\text { Porcentaje de compen- } \\
\text { saciones pagadas por } \\
\text { el fondo de restitución } \\
\text { en municipios de } \\
\text { consolidación }\end{array}$ & - & - & - & - & 100 & 28.6 \\
\hline $\begin{array}{l}\text { Porcentaje de víctimas con } \\
\text { representación judicial en } \\
\text { la URT }\end{array}$ & - & - & 60 & 100 & 70 & 100 \\
\hline $\begin{array}{l}\text { Solicitudes con acto ad- } \\
\text { ministrativo de inclusión } \\
\text { en el Registro de Tierras } \\
\text { Despojadas y Abandona- } \\
\text { das RTDA }\end{array}$ & - & - & - & 1.599 & - & 5.135 \\
\hline $\begin{array}{l}\text { Solicitudes con sentencia } \\
\text { judicial }\end{array}$ & - & - & - & 41 & - & 901 \\
\hline $\begin{array}{l}\text { Solicitudes de ingreso al } \\
\text { RTDA recibidas por la } \\
\text { URT }\end{array}$ & - & - & 13.960 & 31.318 & 72.880 & 54.063 \\
\hline $\begin{array}{l}\text { Solicitudes de restitución } \\
\text { en trámite ante los jueces } \\
\text { especializados en restitu- } \\
\text { ción de tierras }\end{array}$ & - & - & - & - & - & 3.053 \\
\hline $\begin{array}{l}\text { Titulares de las solicitudes } \\
\text { de restitución identificados } \\
\text { en las sentencias }\end{array}$ & - & - & - & - & - & 1.372 \\
\hline $\begin{array}{l}\text { Titulares de las solicitudes } \\
\text { de restitución pendientes } \\
\text { del fallo judicial }\end{array}$ & - & - & - & - & - & 1.982 \\
\hline $\begin{array}{l}\text { Título de baldíos a entida- } \\
\text { des de derecho público en } \\
\text { zonas de consolidación }\end{array}$ & 73 & 73 & 15 & 15 & 10 & 0 \\
\hline
\end{tabular}




\begin{tabular}{|c|c|c|c|c|c|c|}
\hline \multirow[t]{2}{*}{ Indicador/Año } & \multicolumn{2}{|c|}{2011} & \multicolumn{2}{|c|}{2012} & \multicolumn{2}{|c|}{2013} \\
\hline & Meta & Resultado & Meta & Resultado & Meta & Resultado \\
\hline $\begin{array}{l}\text { Total hectáreas adjudica- } \\
\text { das a través del Subsidio } \\
\text { Integral de Tierras SIT }\end{array}$ & 18.750 & 5.801 .91 & 18.750 & 3.094 & 18.750 & 19.507 \\
\hline $\begin{array}{l}\text { Nuevos beneficiarios Asis- } \\
\text { tencia Técnica Integral ATI }\end{array}$ & 71.129 & 131.585 & 531.424 & 474.202 & 316.800 & 389.212 \\
\hline $\begin{array}{l}\text { Nuevos beneficiarios de } \\
\text { ATI alianzas productivas }\end{array}$ & 6.480 & 7.188 & 10.920 & 10.635 & 10.800 & 12.358 \\
\hline $\begin{array}{l}\text { Hectáreas asignadas a } \\
\text { través de SIT a población } \\
\text { campesina }\end{array}$ & 11.250 & 1.125 & 11.250 & 1.756 & 11.250 & $10.472,2$ \\
\hline $\begin{array}{l}\text { Familias campesinas bene- } \\
\text { ficiadas con SIT }\end{array}$ & 1.875 & 211 & 1.875 & 278 & 1.875 & 1.715 \\
\hline $\begin{array}{l}\text { Hectáreas asignadas a } \\
\text { través de SIT a población } \\
\text { desplazada }\end{array}$ & 7.500 & $4.676,9$ & 7.500 & $1.338,2$ & 7.500 & $9.039,2$ \\
\hline $\begin{array}{l}\text { Nuevos beneficiarios de } \\
\text { ATI oportunidades rurales }\end{array}$ & 6.000 & 4.379 & 2.514 & 7.069 & 6.000 & 11.816 \\
\hline $\begin{array}{l}\text { Familias desplazadas bene- } \\
\text { ficiadas con SIT }\end{array}$ & 1.900 & 713 & 1.900 & 220 & 1.900 & 1.452 \\
\hline $\begin{array}{l}\text { Nuevos beneficiarios } \\
\text { ATI DRE }\end{array}$ & 58.694 & 120.018 & 518.000 & 456.498 & 300.000 & 365.038 \\
\hline $\begin{array}{l}\text { Total soluciones vivienda } \\
\text { rural }\end{array}$ & 14.750 & 31.720 & 14.750 & 15.805 & 14.750 & 19.299 \\
\hline $\begin{array}{l}\text { Hectáreas tituladas } \\
\text { baldíos + FNA }\end{array}$ & 401.140 & $401.334,51$ & 411.000 & 514.579 & 295.000 & 129.593 \\
\hline $\begin{array}{l}\text { Hectáreas tituladas res- } \\
\text { guardos indígenas }\end{array}$ & 57.265 & $57.265,44$ & 94.875 & 22.960 & 94.875 & 527.287 \\
\hline $\begin{array}{l}\text { Créditos otorgados a } \\
\text { pequeños productores }\end{array}$ & 25 & 27 & 27 & 25.43 & 30 & 25.74 \\
\hline $\begin{array}{l}\text { Numero de micro } \\
\text { créditos otorgados }\end{array}$ & 19.600 & 47366 & 39200 & 55758 & 58.800 & 63.352 \\
\hline $\begin{array}{l}\text { Soluciones de vivienda a } \\
\text { pobladores rurales pobres }\end{array}$ & 11.800 & 29.392 & 11.800 & 12.583 & 11.800 & 14.778 \\
\hline $\begin{array}{l}\text { Solución de vivienda a } \\
\text { desplazados }\end{array}$ & 2.950 & 2.328 & 2.950 & 3.282 & 2.950 & 4.521 \\
\hline
\end{tabular}

Fuente: elaboración de los autores con datos tomados del Sistema Nacional de Evaluación de Gestión y Resultados (SINERGIA). 
Tabla 6. Indicadores, metas y resultados línea estratégica n. ${ }^{\circ} 6$

\begin{tabular}{|l|c|c|c|c|c|c|}
\hline \multirow{2}{*}{ Indicador/Año } & \multicolumn{2}{|c|}{2011} & \multicolumn{2}{c|}{2012} & \multicolumn{2}{c|}{2013} \\
\cline { 2 - 7 } & Meta & Resultado & Meta & Resultado & Meta & Resultado \\
\hline $\begin{array}{l}\text { Protocolos de expor- } \\
\text { tación firmados }\end{array}$ & 106 & 108 & 116 & 129 & 126 & 142 \\
\hline $\begin{array}{l}\text { Zonas libres de plagas } \\
\text { y enfermedades esta- } \\
\text { blecidas }\end{array}$ & 18 & 18 & 20 & 19 & 24 & 20 \\
\hline $\begin{array}{l}\text { Zonas de baja pre- } \\
\text { valencia establecidas }\end{array}$ & 6 & 5 & 7 & 7 & 9 & 8 \\
\hline
\end{tabular}

Fuente: elaboración de los autores con datos tomados del Sistema Nacional de Evaluación de Gestión y Resultados (SINERGIA). 